\title{
A Three-Phase Shunt Active Power Filter with Unified Constant Frequency Integration Control with RLC Connection Circuit
}

\author{
Rokan Ali Ahmed \\ Dept. of Electrical Engineering \\ University of Malaya \\ Lembah Pantai, 50603Kuala Lumpur. \\ E-mail: Rokan_L4@yahoo.com
}

\author{
S. Mekhilef \\ Department of Electrical Engineering \\ University of Malaya, \\ 50603 Kuala Lumpur, Malaysia \\ E-mail: saad@um.edu
}

\author{
Hew Wooi Ping \\ Department of Electrical Engineering \\ University of Malaya, \\ 50603 Kuala Lumpur, Malaysia \\ E-mail: wphew@um.edu.my
}

\begin{abstract}
This paper discusses a Modular Structure Multilevel Inverter (MSMI) with a Unified Constant Frequency Integration Control (UPC) which is used as an Active Power Filter (APF). APF is connected in shunt to the power system in order to sense the non-sinusoidal current drawn by the non-linear load and inject current to the transmission line which compensates the harmonics drawn by the load. This in turn helps having a power factor value close to one at the source side since the source current is forced to follow the source and thus be in phase with it. An APF topology is simulated for different connection parameters and its performance for each case is studied. Finally the results are compared to show that the topology proposed in this paper has a better harmonic reduction.
\end{abstract}

Index Terms-Active power filter, multilevel inverter, nonlinear load, total harmonic distortion (THD)

\section{INTRODUCTION}

The quality of modern life has significantly improved with the rapid developments of power electronics devices which introduce sophisticated energy-efficient and controllable equipments to industries and homes. However, having nonlinear characteristics power electronics devices create power quality problems [1]. When this is considered with the fact that the number of the non-linear loads and power electronics equipment is rapidly increasing the growing concern on the power quality problem can easily be understood [2].

Harmonic distortion is a key phrase used today when talking about power quality. These nonlinear loads generate harmonic and reactive currents, which lead to low power factor, low energy efficiency, and harmful disturbance to other appliances [3]. There are requirements imposed on the connection of the loads to the common coupling point. These are established to ensure that excessive harmonic currents will not be injected into the AC lines, which would affect the quality of power to other users that are sharing the same power line [1]. The utilities tend to bring the harmonic problems under control in order to reduce overstress at the utilities equipments

In order to solve these problems, Power Factor Correction (PFC) techniques and active power filters (APF) are utilized to eliminate the harmonics and improve the power factor. A PFC unit is usually inserted in the energy pass, which processes all the power and corrects the current to unity power factor. PFC techniques are generally suitable for low to medium power applications [3]. APF provides only the harmonic and reactive power to cancel the one generated by the nonlinear loads [4]. In this case, only a small portion of the energy is processed, which may result in overall higher energy efficiency and higher power processing capability [5].

Active power filters (APF) are viable solutions to eliminate the harmonics and improve the power factor. There are many configurations of active filters, such as the series active filter, shunt active filter, and combination of shunt and series active filter. Shunt APF is considered to be the most basic configuration for active power filter. APF is known for its simplicity, reliability and ease of operation [6].

The APF is actually an inverter that is connected at the common point of coupling to produce harmonic components which cancel the harmonic components from a group of nonlinear loads to ensure that the resulting total current drawn from the main incoming supply is sinusoidal. Their size depends on the harmonic current drawn by the nonlinear loads and the required compensation [7].

Although many technical papers related to APFs have been presented during the last decade, majority of them discusses the principles of operation and different schemes for controlling different topologies of APF's only. There is very little concern to the limitation of the APFs to the application voltage range. In fact, and most of the developed APFs are applicable for low power level only due to the semiconductor devices constraints [1].

This paper discusses a new topology of three-phase APF based on Modular Structure Multilevel Inverter (MSMI), which is generally for high voltage/high power applications. The MSMI has many distinct features in terms of its structure, which is simple, modular and also requires the least number of components. These features provide the flexibility in extending the MSMI to higher number of levels without undue increase in circuit complexity as well as facilitate packaging [8]. It provides a low cost and high performance solution for power quality control. 
Most previously reported control approaches need to sense the load current and then calculate the load current harmonics and reactive components in order to generate the reference for controlling the power converters[9], [10]. Article [11] introduced a promising solution based on onecycle control [12], and mains current sensing for a singlephase APF. With one-cycle control, the multipliers and voltage sensors in the control loop are eliminated and the control circuitry is simple and robust. In this paper, a threephase APF with Unified Constant frequency Integration (UCI) control is proposed based on one-cycle control. Only one current sensor and one voltage sensor (resister divider) are used to sense the ac main current and the voltage across the dc capacitor. The control method features constant switching frequency operation, minimum reactive and harmonic current generation, and simple analog circuitry.

This paper is organized as follows:

The proposed three phase APF, including the power stage and control circuitry, is described in Section II. This control method is used to control a family of inverters and the simulating results are given in Section III. Section IV gives a conclusion.

\section{SySTEM CONFIGURATION}

The structure of a wye connected five-level three-phase MSMI is as shown in Fig.1, which consists of two cascaded inverter per phase, where each inverter has two legs, also, each leg has two switches. MSMI APF in each phase produces current that has the same magnitude with that generated by the nonlinear load, but different in phase, so that the net resultant current is pure sinusoidal. The capacitor is charged from the source during the operation of the inverter switching. Voltage divider is also installed at the APF which sends the divided voltage to the controller.

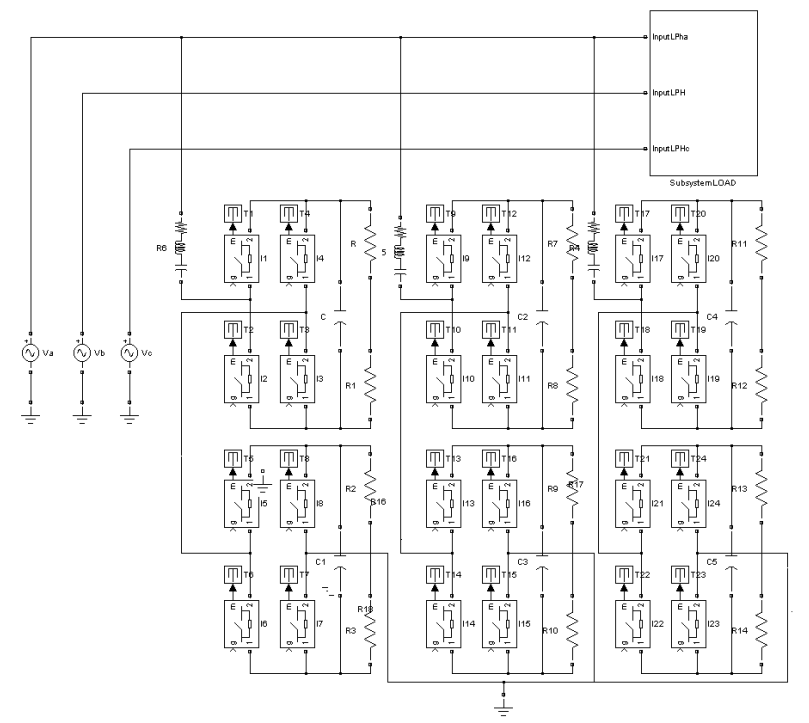

Fig.1. 5-level three-phase wye connected MSMI

Each phase has an input RLC circuit. When APF is used typically an inductor is needed at the input [13]. The thesis in [6] introduces an RL circuit at the input.

In this paper a capacitor is introduced to the input circuitry and the resultant performance is studied. The results are given and discussed in Simulation Results section.
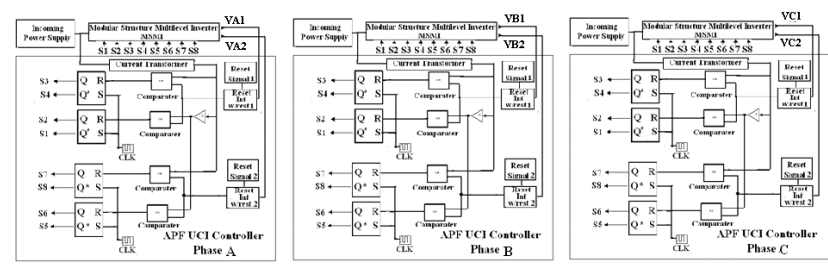

Fig.2. Block diagram for control of a 5-level three phase MSMI

Fig. 2 shows the proposed block diagram of the five-level three phase MSMI controller, where $\mathrm{V}_{\mathrm{A} 1}, \mathrm{~V}_{\mathrm{A} 2}, \mathrm{~V}_{\mathrm{B} 1}, \mathrm{~V}_{\mathrm{B} 2}$, $\mathrm{V}_{\mathrm{C} 1}, \mathrm{~V}_{\mathrm{C} 2}$ are the DC voltages of the inverter capacitors for the phases $\mathrm{A}, \mathrm{B}$ and $\mathrm{C}$ respectively. For each module in each phase, the DC voltage and the source current are sensed and sent to the controller. The DC capacitor voltage is integrated and compared with the source current then the output of the comparator is entered to an R-S flip flop to generate the pulses, which turn OFF and turn ON the switches, based on the function of the R-S flip flop. This operation of integration starts when it gets pulse from the clock pulse. The ports $\mathrm{Q}$ and $\mathrm{Q}^{*}$ are generated based on the condition that is required for compensation. The R-S flip flop will receive two signals; one from the comparator through $\mathrm{R}$ input port while the other signal from the clock through $\mathrm{S}$ input port. The period of the clock pulses determines the constant switching frequency operation of the MSMI while the integrator will reset when the next clock pulse triggers it [1].

The control objective of the full-bridge inverter is to provide the reactive and harmonic current required by the nonlinear load, so that the net current draws from the AC main is the fundamental active power used at the nonlinear load. The control key equations for the UCI controller are derived for the three phase MSMI based on the work presented in [14] and [13]. During the positive half cycle the phase voltages for each phase (Vga, $\mathrm{Vgb}, \mathrm{Vgc}$ ) are greater than zero, $\mathrm{S} 1$ is always $\mathrm{ON}$ in each phase. The inductor voltages will be as follows,

$$
\begin{array}{lll}
\mathrm{V}_{\mathrm{LA}}(\mathrm{ON})=\mathrm{V}_{\mathrm{ga}} & \text { for } & 0<\mathrm{t}<\mathrm{d}_{\mathrm{A}} \mathrm{T}_{\mathrm{S}} \\
\mathrm{V}_{\mathrm{LB}}(\mathrm{ON})=\mathrm{V}_{\mathrm{gb}} & \text { for } & 0<\mathrm{t}<\mathrm{d}_{\mathrm{B}} \mathrm{T}_{\mathrm{S}} \\
\mathrm{V}_{\mathrm{LC}}(\mathrm{ON})=\mathrm{V}_{\mathrm{gc}} & \text { for } & 0<\mathrm{t}<\mathrm{d}_{\mathrm{C}} \mathrm{T}_{\mathrm{S}}
\end{array}
$$

and

$$
\begin{aligned}
& V_{\mathrm{LA}}(\text { OFF })=\mathrm{V}_{\mathrm{ga}}-\mathrm{V}_{\mathrm{O}}= \begin{cases}\mathrm{V}_{\mathrm{ga}}-\mathrm{V}_{\mathrm{dc}}, & \mathrm{d}_{\mathrm{A}}=\mathrm{d} 1 \\
\text { for } \mathrm{d}_{\mathrm{A}} \mathrm{T}_{\mathrm{S}}<\mathrm{t}<\mathrm{T}_{\mathrm{S}} \\
\mathrm{V}_{\mathrm{ga}}-2 \mathrm{~V}_{\mathrm{dc}}, & \mathrm{d}_{\mathrm{A}}=\mathrm{d} 2\end{cases} \\
& \mathrm{V}_{\mathrm{LB}}(\text { OFF })=\mathrm{V}_{\mathrm{gb}}-\mathrm{V}_{\mathrm{O}}= \begin{cases}\mathrm{V}_{\mathrm{gb}}-\mathrm{V}_{\mathrm{dc}}, & \mathrm{d}_{\mathrm{B}}=\mathrm{d} 1 \\
& \text { for } \mathrm{d}_{\mathrm{B}} \mathrm{T}_{\mathrm{S}}<\mathrm{t}<\mathrm{T}_{\mathrm{S}} \\
\mathrm{V}_{\mathrm{gb}}-2 \mathrm{~V}_{\mathrm{dc}}, & \mathrm{d}_{\mathrm{B}}=\mathrm{d} 2\end{cases} \\
& \mathrm{V}_{\mathrm{LC}}(\text { OFF })=\mathrm{V}_{\mathrm{gc}}-\mathrm{V}_{\mathrm{O}}= \begin{cases}\mathrm{Vc}_{\mathrm{gc}}-\mathrm{V}_{\mathrm{dc}}, & \mathrm{d}_{\mathrm{C}}=\mathrm{d} 1 \\
\mathrm{~V}_{\mathrm{gc}}-2 \mathrm{~V}_{\mathrm{dc}}, & \mathrm{d}_{\mathrm{C}}=\mathrm{d} 2\end{cases}
\end{aligned}
$$


where $\mathrm{d}_{\mathrm{A}}, \mathrm{d}_{\mathrm{B}}$ and $\mathrm{d}_{\mathrm{C}}$ are duty ratios and $\mathrm{V}_{\mathrm{g}}$ and $\mathrm{V}_{\mathrm{O}}$ are input AC voltage for each phase and DC bus voltage of the APF, respectively. For constant frequency operation, the average inductor in voltage-second of each phase is approximately balanced during each switching cycle, that is;

$$
\begin{aligned}
& V_{L A}(O N) \cdot d_{A} T_{S}+V_{L A}(O F F) \cdot\left(1-d_{A}\right) T_{S}=0 \\
& V_{L B}(O N) \cdot d_{B} T_{S}+V_{L B}(O F F) \cdot\left(1-d_{B}\right) T_{S}=0 \\
& V_{L C}(O N) \cdot d_{C} T_{S}+V_{L C}(O F F) \cdot\left(1-d_{C}\right) T_{S}=0
\end{aligned}
$$

By substituting (1) and (2) into (3)

$$
\begin{array}{rr}
V_{g a} \cdot d_{A} T_{S}+\left(V_{g a}-V_{O}\right) \cdot\left(1-d_{A}\right) T_{S}=0 & \text { when } V_{g a}>0 \\
V_{g b} \cdot d_{B} T_{S}+\left(V_{g b}-V_{O}\right) \cdot\left(1-d_{B}\right) T_{S}=0 & \text { when } V_{g b}>0 \\
V_{g c} \cdot d_{C} T_{S}+\left(V_{g c}-V_{O}\right) \cdot\left(1-d_{C}\right) T_{S}=0 & \text { when } V_{g c}>0
\end{array}
$$

Similarly for the negative half cycle,

$$
\begin{array}{cc}
V_{g a} \cdot d_{A} T_{S}+\left(V_{g a}+V_{O}\right) \cdot\left(1-d_{A}\right) T_{S}=0 & \text { when } V_{g a}<0 \\
V_{g b} \cdot d_{B} T_{S}+\left(V_{g b}+V_{O}\right) \cdot\left(1-d_{B}\right) T_{S}=0 & \text { when } V_{g b}<0 \\
V_{g c} \cdot d_{C} T_{S}+\left(V_{g c}+V_{O}\right) \cdot\left(1-d_{C}\right) T_{S}=0 & \text { when } V_{g c}<0
\end{array}
$$

Suppose,

$$
\mathrm{V}_{\mathrm{ge}}=\left\{\begin{array}{lll}
\mathrm{V}_{\mathrm{g}} \\
-\mathrm{V}_{\mathrm{g}}
\end{array} \text { and } i_{\mathrm{g}}=\left\{\begin{array}{ccc}
i_{\mathrm{g}} & \text { for } & \mathrm{V}_{\mathrm{g}}>0 \\
-i_{\mathrm{g}} & \text { for } & \mathrm{V}_{\mathrm{g}}<0
\end{array}\right.\right.
$$

The combination of (3), (4) and (5) yields the relationship between duty ratios of the switches, input $\mathrm{AC}$ voltage for each phase and DC bus voltage of the APF.

$$
\begin{aligned}
& \mathrm{V}_{\text {gea }}=\mathrm{V}_{\mathrm{O}}\left(1-\mathrm{d}_{\mathrm{A}}\right) \\
& \mathrm{V}_{\text {geb }}=\mathrm{V}_{\mathrm{O}}\left(1-\mathrm{d}_{\mathrm{B}}\right) \\
& \mathrm{V}_{\text {gec }}=\mathrm{V}_{\mathrm{O}}\left(1-\mathrm{d}_{\mathrm{C}}\right)
\end{aligned}
$$

In order to achieve three phase unity power factor, the control goal of the APF is therefore to force the AC current to follow the $\mathrm{AC}$ input voltage. For each phase, with Rs as the equivalent sensing resistance,

$\mathrm{V}_{\mathrm{ge}}=\mathrm{R}_{\mathrm{S} .} i_{\mathrm{ge}}$

Equations (6) and (7), yield the control key equations as follows,

$$
\begin{aligned}
& \mathrm{R}_{\mathrm{Sa}} i_{\mathrm{gea}}=\mathrm{V}_{\mathrm{O}}\left(1-\mathrm{d}_{\mathrm{A}}\right) \\
& \mathrm{R}_{\mathrm{Sb}} i_{\mathrm{geb}}=\mathrm{V}_{\mathrm{O}}\left(1-\mathrm{d}_{\mathrm{B}}\right) \\
& \mathrm{R}_{\mathrm{Sc}} i_{\mathrm{gec}}=\mathrm{V}_{\mathrm{O}}\left(1-\mathrm{d}_{\mathrm{C}}\right)
\end{aligned}
$$

The direct relationship between input AC currents, duty ratios of the switches and DC bus voltage of the APF is given in equation (8). The control system, which generates the gating signals of switches in the inverter, changes the duty of cycle of these signals so that the control of phase currents is sustained. This in turn makes the control of AC current possible. In short by changing duty cycle of the gate signals the control makes the AC current in phase with AC voltage

\section{SimULATION RESUlTS}

The simulation studies are carried out for three different cases. The first case is the ordinary transmission system with the three phase source, transmission line and the nonlinear load. This case is studied to examine the characteristics of the non-linear load and the line voltage and currents when it is connected.

The second and thirds cases are when the multi-level inverter (Active Power Filter) is connected to the transmission line as shunt controller in order to compensate the harmonics drawn by the non-linear load. The difference between the two cases is the circuitry which is used to connect the inverter to the transmission line. In the second case this circuitry is designed as resistance and inductance and this is studied in detail [6]. In this project a capacitor is introduced to the connection circuitry and the resultant performance of APF is studied.

The non-linear load is composed of a diode rectifier circuit with an RC circuit at the output. In Fig. 3, the current drawn by the non-linear can be observed.

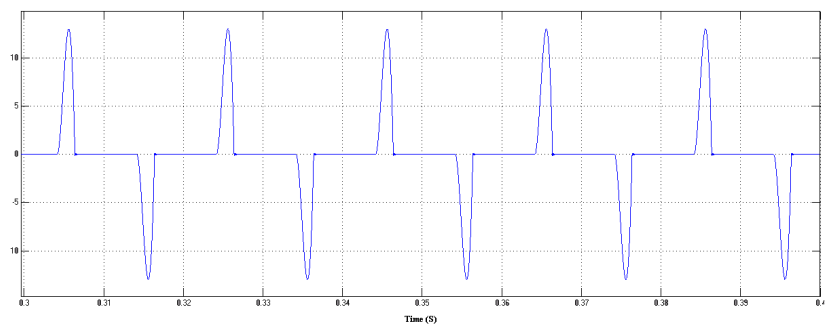

Fig.3. Waveform of source current before compensation for phase A

Because of its non-sinusodial waveform this current has very high harmonic content. The FFT analysis of the current supplied by the source and its harmonic content is given in Fig. 4.

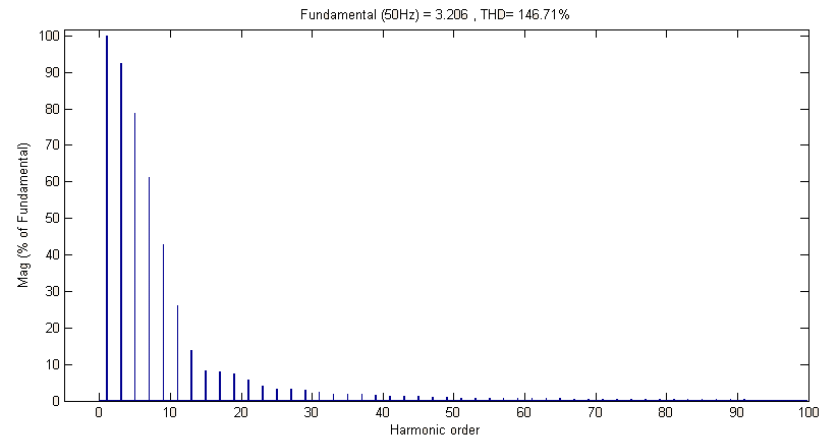

Fig.4. Harmonic spectrum source current before compensation for phase $\mathrm{A}$

When the Active Power Filter is connected to the system the controller generates necessary gating signals so that the output current of the inverter negates the harmonics drawn by the non linear load. The resultant source current is in 
phase with the source voltage which implies that the power factor is close to 1 .

The waveform given in Fig. 5, is the source current after compensation for phase A. The FFT analysis of the new source current is given in Fig. 6, where the harmonic content can also be observed.

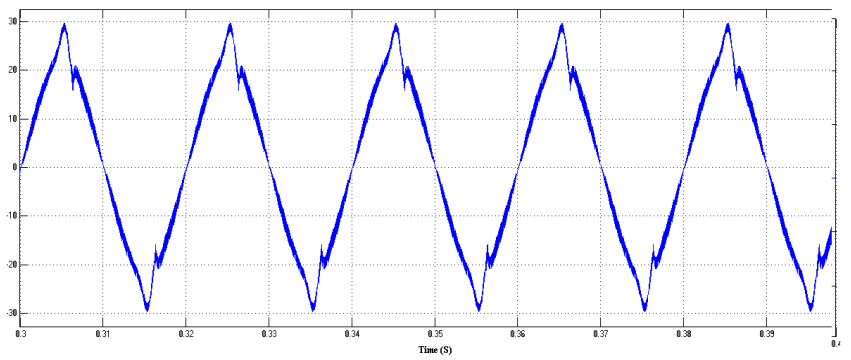

Fig.5. Waveform of source current after compensation for phase A by using RL

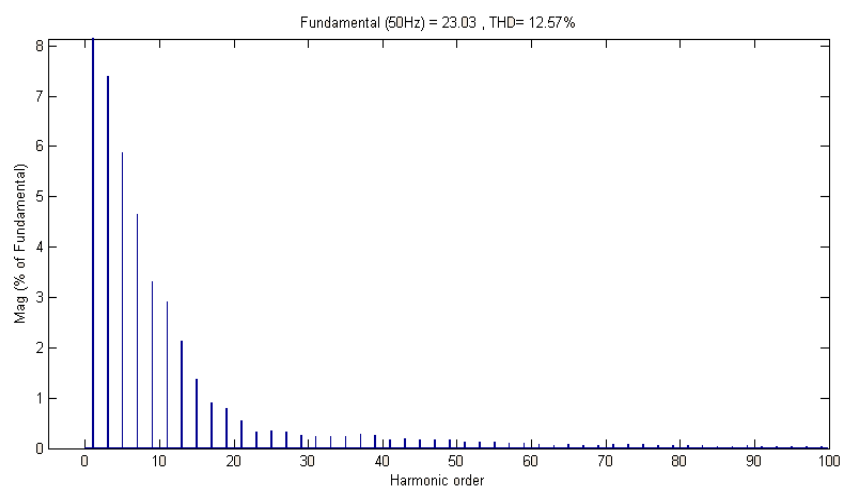

Fig.6. Harmonic spectrum of source current after compensation for phase A by using RL

Then, the last simulation is performed after making a slight change in the circuitry between the transmission line and the multi-level inverter. A capacitor is connected in series with already existing resistive and inductor.

The new performance of the Active Power Filter is much better than the previous case. The level of Total Harmonic Distortion (THD) decreased from $12.57 \%$ in RL case to around $5.72 \%$ in RLC case.

The source current for the phase A can be observed in Fig. 7.

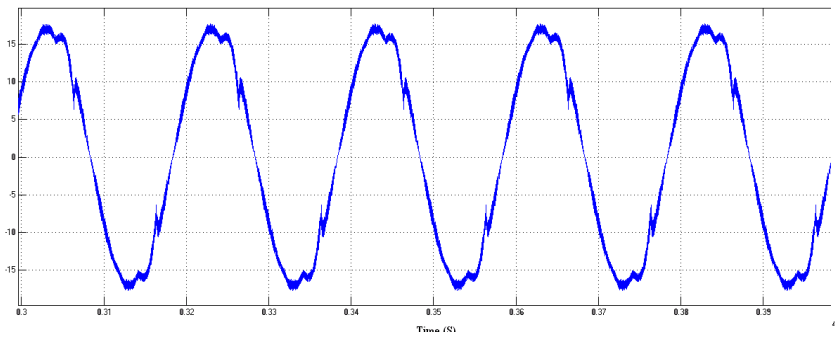

Fig.7. Waveform of source current after compensation for phase A by using RLC

The FFT analysis given below in Fig.8, depicts the harmonic content of the source current. It also shows that the THD content is pulled down to $5.72 \%$ with the introduction of the capacitor.

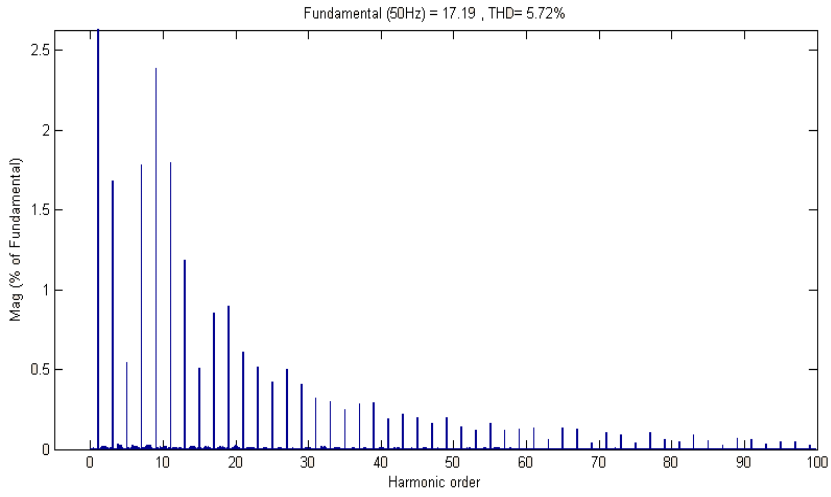

Fig.8. Harmonic spectrum of source current after compensation for phase A by using RLC

Table I below, summarizes the data collected from the simulation studies. The first column presents the system when the non-linear is connected to the power system and no power filtering is performed. Thus, a huge amount of harmonic current flows through the transmission line.

The second column presents the Total Harmonic Distortion when the proposed Active Power Filter is connected to the system through an RL circuit. There is significant enhancement in THD characteristics since it is pulled down from $146 \%$ to $12.5 \%$.

The last column shows the data for the simulation which is unique to this paper where the APF is connected to the Transmission Line through an RLC circuit. The THD value is dropped further to $\% 5.7$ for phase A.

TABLE I. Total Harmonic Distortion for Different Cases

\begin{tabular}{|l|c|c|c|}
\hline & Non-linear load & RL & RLC \\
\hline Phase A & $146.71 \%$ & $12.57 \%$ & $5.72 \%$ \\
\hline Phase B & $146.71 \%$ & $12.09 \%$ & $5.97 \%$ \\
\hline Phase C & $146.71 \%$ & $12.19 \%$ & $5.95 \%$ \\
\hline
\end{tabular}

\section{CONCLUSION}

The operation principles of an active power filter comprising of Modular Structure Multilevel Inverter (MSMI) and Unified Constant frequency Integration Control (UPI) are described in this paper. The performance of a topology which is present in the literature [6] is studied in detail for two cases. Being unique to this work, a capacitor is introduced to the circuitry that is used to connect the multi level inverter to the transmission line.

Extensive simulation works are carried out and the performance of the Active Power Filter is studied. The change that is done in the connection circuit proved to be very beneficial and decreased the total harmonic distortion to $5.72 \%$. The operation of the multi-level inverter and the control strategy is confirmed. Furthermore the positive effect of the introduction of the capacitor to the connection circuit is proved. 


\section{REFERENCES}

[1] L.P. YI."Modular Structured Multilevel Inverter as Active Power Filter with Unified Constant-Frequency Integration control,’ Master of Engineering (Electrical-Power), UTM 2005.

[2] Integrated Publishing, Electrical Engineering Training Series, http://www.tpub.com/neets/book23/101a.htm.

[3] C.Qiao and K.M. Smedley, "Three-phase Active Power Filters with Unified Constant-frequency Integration Control," Power Electronics and Motion Control Conference, vol. 2, pp. 698 - 705, Aug. 2000.

[4] L. Zhou and K. Smedley. "Unified Constant-frequency Integration Control of Active Power Filters," in Proc. 32nd IEEE Applied Power Electronics Conference and Exposition,( APEC),. Vol. 1, pp. 406 412 , Feb 2000

[5] H. Akagi,Y.Kanazawa, and A. Nabae "Instantaneous reactive power compensation comprising switching devices without. energy components" IEEE Trans. Industrial Applications, vol.IA-20, no. 3, pp. 625-630, May/June 1984.

[6] A. I. Ismaail, "Modular Structured Multilevel Inverter as A ThreePhase Shunt Active Power Filter with Unified Constant-Frequency Integration Control," Master of Engineering Thesis, UTM 2007.

[7] B.Segal, Power Correction Systems, Inc. (2000), "Costs And Benefits OF Harmonic Current And Power Factor Reduction For Variable Speed Drives In An Industrial Facility." http://www.activeharmonicfilters.com

[8] F. Z. Peng, J. Lai, J. McKeever and J. VanCOevering "A Multilevel Voltage-Source Inverter with Separate DC Sources for Static Var Generation," in Conf. Rec. 30th IEEE IAS Annu. Meeting,1995, vol. 3, pp. 2541-2548,Oct. 1995.

[9] H. Akagi, A. Nabae, and S. Ato," Control Strategy of Active Power Filters Using Multiple Voltage-Source PWM Converters,'IEEE Trans. Power Electron. Industry Applications, vol. IA-22, no. 3, pp. 460-465, May 1986.

[10] Nakata, A.; Ueda, A.; Torii, A. "A method of detection for an active power filter applying moving average to pq-theory," in Proc. 29th IEEE Power Electron. Specialist Conf., Fukuoka, Japan, pp. 242-247, June 2001 .

[11] K.M. Smedley, L. Zhou and C. Qiao," "Unified constant-frequency integration control of active power filters-steady-state and dynamics," IEEE Trans. Power Electron., vol. 16, no. 3, pp. 428-436, May 2001.

[12] S. Cuk, and K.M. Smedley, "One-cycle control of switching converter," IEEE Trans. Power Electron., vol. 10, no. 6, pp. 625-633, Nov. 1995.

[13] N. A. Azli and P. Y. Lim, "Modular Structured Multilevel Inverter with Unified Constant-Frequency Integration Control for Active Power Filters," International Conference on Power Electronics and Drives Systems,( PEDS), Vol. 2, pp . 1312 - 1316, Nov. 2005

[14] C. Qiao , K. M. Smedley and F. Maddaleno, "A Comprehensive Analysis and Design of a Single Phase Active Power Filter with Unified Constant-frequency Integration Control," in Proc. 32nd IEEE Power Electron. Specialist Conf., Vancouver, BC, Canada , pp. 1619 - 1625, June 2001. 